\title{
Differential glucocorticoid-induced closure of the blood-milk barrier during lipopolysaccharide- and lipoteichoic acid-induced mastitis in dairy cows
}

\author{
Samantha K. Wall, ${ }^{*} \dagger$ Lorenzo E. Hernández-Castellano, ${ }^{*}$ Amir Ahmadpour, ${ }^{*}$ Rupert M. Bruckmaier, \\ and Olga Wellnitz ${ }^{* 1}$ \\ *Veterinary Physiology, Vetsuisse Faculty, and \\ †Graduate School for Cellular and Biomedical Science, University of Bern, 3012 Bern, Switzerland
}

\begin{abstract}
Bacteria invading the mammary gland can cause pathogen-dependent differences in the permeability of the blood-milk barrier leading to the differential paracellular transfer of blood and milk components. Glucocorticoids such as prednisolone (PRED) are known to increase the integrity of the blood-milk barrier and quickly restore the decreased milk quality associated with mastitis. The objective of this study was to examine the effect of intramammary PRED on the differential permeability of the blood-milk barrier during mastitis induced by lipopolysaccharide (LPS) from Escherichia coli or lipoteichoic acid (LTA) from Staphylococcus aureus. Thirty-one dairy cows, divided into 6 groups, were injected via a teat canal with LPS, LTA, LPS and PRED, LTA and PRED, saline (control), or PRED. Milk and blood samples were collected 0 to $8 \mathrm{~h}$ after challenge and analyzed for somatic cell count, IgG, serum albumin, and lactate dehydrogenase in milk, or $\alpha$-lactalbumin in plasma. Somatic cell count was similarly elevated in LPS- and LTA-challenged quarters and was reduced to control quarter levels only in LTA-challenged quarters with PRED administration. Lactate dehydrogenase activity was highly elevated in LPS quarters and only slightly elevated in LTA quarters, but decreased to control quarter levels with PRED administration. For serum albumin and IgG, only LPS quarters showed an elevation in concentration and PRED treatment reduced the concentration to control quarter level. We found no differences in $\alpha$-lactalbumin concentrations in plasma in PRED-treated cows compared with cows that only received LPS or LTA. In conclusion, the pathogen-specific appearance of blood constituents in milk during mastitis demonstrates a differential activation of the blood-milk barrier that, in turn, can be manipulated by intramammary glucocorticoids. The results show that the administration of
\end{abstract}

Received February 26, 2016.

Accepted May 27, 2016.

${ }^{1}$ Corresponding author: olga.wellnitz@vetsuisse.unibe.ch
PRED during mastitis increases the blood-milk barrier integrity but has implications in reducing the transfer of IgG that specifically occurs during E. coli mastitis. In addition, it can also reduce the number of migrating immune cells dependent on the mastitis-inducing pathogen. Potential effects of PRED on the cure of naturally occurring mastitis have to be taken into consideration.

Key words: mastitis, blood-milk barrier, glucocorticoid, endotoxin

\section{INTRODUCTION}

Mastitis, an inflammation of the udder, is usually caused by bacterial pathogens invading the mammary gland and can cause pain and changes in milk composition. Common pathogens, namely Escherichia coli, a gram-negative bacterium typically associated with acute clinical mastitis, and Staphylococcus aureus, a grampositive bacterium typically associated with subclinical chronic mastitis, can cause differential activation of the immune system (Wellnitz and Bruckmaier, 2011). In addition, during an immune response, the blood-milk barrier can become leaky, allowing for the paracellular transfer of blood components into milk and vice versa (Nguyen and Neville, 1998). Activation of the immune system and the leaky blood-milk barrier can be experimentally induced by using an intramammary injection of specific endotoxins embedded in the bacterial cell wall: LPS, representing E. coli, and lipoteichoic acid (LTA), representing $S$. aureus.

Although antibiotics are generally used to treat mastitis, prednisolone (PRED), a glucocorticoid, is increasingly added to antibiotic formulations in Europe to aid in the restoration of milk quality and reducing inflammation (Sipka et al., 2013). This glucocorticoid is known to increase the integrity of the blood-milk barrier in cows challenged with LPS (Wellnitz et al., 2014), and it has been shown that glucocorticoids can induce the formation of tight junctions (junctional complexes between mammary epithelial cells) in mouse mammary cells (Zettl et al., 1992). In turn, PRED can bind to the 
glucocorticoid receptor on cells, blocking the production of proinflammatory cytokines (Stahn et al., 2007), and, importantly, it can affect the recruitment of cells to sites of inflammation due to this modification in cytokine and chemokine production (Schwiebert et al., 1996).

To evaluate the effect of PRED on the blood-milk barrier and its permeability, the measurement of bloodderived proteins in milk, including serum albumin (SA), IgG, and lactate dehydrogenase (LDH; Stelwagen et al., 1994; Lehmann et al., 2013; Wall et al., 2015), can be used as indicators of a permeable barrier. Alternatively, specific milk proteins can be found in the blood during mastitis. $\alpha$-Lactalbumin, a subunit of lactose synthase, can be elevated in the blood and is also indicative of increased permeability of the bloodmilk barrier (McFadden et al., 1987; Wall et al., 2015).

Ours is the first study that the effects of PRED have been examined in both LPS- and LTA-induced mastitis as a comparative study. The aim of this study was to examine the effect of intramammary PRED on the permeability of the blood-milk barrier in cows challenged with LPS from E. coli or LTA from $S$. aureus and to determine its suitability as an addition to mastitis therapies. We have tested the hypothesis that intramammary PRED administration induces a differential reduction of blood-milk barrier permeability during mastitis induced either by LPS or LTA.

\section{MATERIALS AND METHODS}

\section{Animals}

All animal trials were approved and permitted by the Cantonal Committee of Animal Experiments, Fribourg, Switzerland, and all experimental procedures followed the Swiss law of animal protection. Thirty-one dairy cows [Holstein Friesian $(\mathrm{n}=23)$, Red Holstein $(\mathrm{n}=4)$, Swiss Fleckvieh $(\mathrm{n}=4)$ ] in mid lactation (mean DIM = $189.4 \pm 14.58)$ were selected. Parities of experimental cows ranged from 1 to 6 and cows were producing $>15$ $\mathrm{L}$ of milk/d (mean milk yield $=19.9 \pm 0.67 \mathrm{~L} / \mathrm{d}$ ). All cows had an SCC $<150 \times 10^{3}$ cells $/ \mathrm{mL}$ in all 4 quarters during the $3 \mathrm{~d}$ before the experiment and showed no signs of clinical mastitis. Overall health status was determined by a blood glutaraldehyde coagulation test (Sandholm, 1976) before the experiment. Cows were housed at the Agroscope research station (Posieux, Switzerland) in straw- and sawdust-bedded tiestalls for the duration of the experiment. Cows were fed roughage ad libitum and $1 \mathrm{~kg}$ of energy concentrate daily. Water was also available ad libitum. Cows were machine milked regularly twice daily at 0530 and $1600 \mathrm{~h}$.

\section{Experimental Procedures and Treatments}

The day before the experiment, sterile milk samples for bacteriological culture were aseptically taken from all quarters, according to Hogan et al. (1999), and frozen until culture. Jugular catheters (length of $105 \mathrm{~mm}$, diameter of $1.9 \times 2.4 \mathrm{~mm},-13$ gauge; Vygon, Ecouten, France) were inserted and immediately flushed with $0.9 \% \mathrm{NaCl}$ and 5,000 IU of heparin (Laboratoire Dr. G. Bichsel SA, Interlaken, Switzerland) to prevent blood clotting overnight.

On the day of the experiment, cows were randomly allocated to 6 treatment groups [group 1 (LPS), $\mathrm{n}=$ 7; group 2 (LTA), $\mathrm{n}=6$, group 3 (control cow), $\mathrm{n}=4$; group 4 (LPS PRED), $\mathrm{n}=6$; group 5 (LTA PRED), $\mathrm{n}$ $=5$; group 6 (control cow PRED), $\mathrm{n}=3$ ]. Immediately following morning milking, 2 quarters from each cow were injected via a teat canal and each quarter received a co-injection of 2 treatments from separate sterile syringes according to Figure 1. The injections were performed by sterilizing each teat with gauze soaked in $70 \%$ ethanol and inserting a sterilized teat cannula. An upwards massage was performed for $15 \mathrm{~s}$ immediately after injection to move the injection fluid into the parenchyma. Treatments were prepared as follows: $0.2 \mu \mathrm{g}$ of LPS (from E. coli serotype O26:B6, Sigma-Aldrich, St. Louis, MO) diluted in $10 \mathrm{~mL}$ of $0.9 \%$ sterile saline; $20 \mu \mathrm{g}$ of LTA (from S. aureus, Sigma-Aldrich) diluted in $10 \mathrm{~mL}$ of $0.9 \%$ sterile saline; $30 \mathrm{mg}$ of PRED (prednisolone sodium phosphate, Santa Cruz Biotechnology, Dallas, TX) diluted in $10 \mathrm{~mL}$ of double-distilled water. The control treatment was $10 \mathrm{~mL}$ of $0.9 \%$ sterile saline. Appropriate dosages of LPS, LTA, and PRED were selected by performing a preliminary experiment and dosages of LPS and LTA were chosen that induced a similar SCC increase. Each cow had one treatment and one control quarter. Time of injection was designated as time 0 .

\section{Temperature, Milk, and Blood Samples}

The rectal temperature of the cows was measured immediately before injection and every $\mathrm{h}$ until $8 \mathrm{~h}$ postchallenge. Milk and blood samples were taken every $30 \mathrm{~min}$ between 0 and $1 \mathrm{~h}$, every $15 \mathrm{~min}$ between 1 and $4 \mathrm{~h}$, and every $30 \mathrm{~min}$ between 4 and $8 \mathrm{~h}$. Blood samples were collected from the jugular catheter and were placed into tubes containing tripotassium EDTA. Blood was stored on wet ice until centrifugation at $2,500 \times g$ for $20 \mathrm{~min}$ at $4^{\circ} \mathrm{C}$ to obtain plasma which was stored at $-20^{\circ} \mathrm{C}$ until analysis. Milk samples were processed immediately for SCC then stored at $-20^{\circ} \mathrm{C}$. 


\section{Laboratory Analyses}

Bacteriology Samples. Analysis of bacteriology samples was performed according to Hogan et al. (1999) standards. In brief, from each thawed sample, $10 \mu \mathrm{L}$ of milk was streaked onto a quadrant of a $7 \%$ bovine blood agar plate containing $0.05 \%$ esculin (Merck KGaA, Darmstadt, Germany) and incubated aerobically for 24 to $48 \mathrm{~h}$ at $37^{\circ} \mathrm{C}$. Samples were considered to be culture positive if one or more colonies were observed $(\geq 100$ $\mathrm{cfu} / \mathrm{mL}$ ). Identification of bacteria was done by Gram staining, inspection of the colony morphology, and biochemical testing. Catalase tests were performed to differentiate gram-positive cocci as catalase-positive or -negative. Samples yielding 3 or more different bacterial species were considered to be contaminated.

$\boldsymbol{S C C}$. Milk samples were processed for SCC using a DeLaval cell counter (DCC, DeLaval, Tumba, Sweden) according to the manufacturer's protocol. Samples were diluted 1:10 in commercially available milk if the cell count was $>3 \times 10^{6}$ because the detection limit for the cell counter is between $3 \times 10^{6}$ and $4 \times 10^{6}$ cells $/ \mathrm{mL}$.

LDH Activity. For LDH measurement, milk serum was obtained by a 2-step process (centrifugation at $4,000 \times g$ for $15 \mathrm{~min}$ at $4^{\circ} \mathrm{C}$, then $14,000 \times g$ for $30 \mathrm{~min}$ at $\left.4^{\circ} \mathrm{C}\right)$. Lactate dehydrogenase activity was measured in milk serum by a commercial kit (AxonLab AG, Baden, Switzerland; cross-reacts with bovine
LDH) using the COBAS MIRA automated analyzer (Roche Diagnostics, Basel, Switzerland) according to the manufacturer's instructions. The limit of detection was $0.01 \mathrm{mmol} / \mathrm{L}$.

$\boldsymbol{I} \boldsymbol{g} \boldsymbol{G}$. The concentration of $\operatorname{IgG}$ in milk was analyzed by ELISA using a bovine-specific commercial kit (Bethyl Laboratories, Montgomery, TX) according to the manufacturer's instructions with slight modifications (Lehmann et al., 2013). In brief, samples were diluted in wash buffer (50 $\mathrm{m} M$ Tris, $0.14 \mathrm{M} \mathrm{NaCl}, 0.05 \%$ Tween 20 , adjusted to $\mathrm{pH} 8.0$ ) to ensure the samples were in range of the standards. The primary and secondary antibodies were diluted 1:200 and 1:100,000, respectively. The standard curve was adjusted to $400,300,150,75$, $37.5,18.75$, and $9.375 \mathrm{ng} / \mathrm{mL}$. Samples were blocked in blocking buffer containing 5\% fish skin gelatin (SigmaAldrich) diluted in double-distilled water. Absorbance measurements were read on the Synergy Mx plate reader (BioTek Instruments, Winooski, VT). The limit of detection was $9.375 \mathrm{ng} / \mathrm{mL}$. The inter- and intraassay coefficients of variation were 6.93 and $8.80 \%$, respectively. All samples were performed in duplicate.

$\boldsymbol{S A}$. The concentration of SA in milk samples was analyzed by ELISA using a bovine-specific commercial kit (Bethyl Laboratories) according to the manufacturer's instructions. Milk samples were diluted in wash buffer (50 mM Tris, $0.14 M \mathrm{NaCl}, 0.05 \%$ Tween 20, adjusted to $\mathrm{pH} 8.0$ ) to ensure the samples were in range
A.

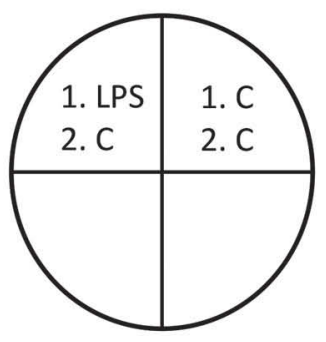

D.

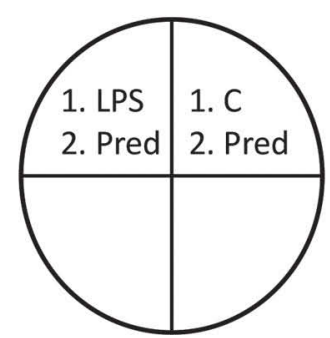

B.

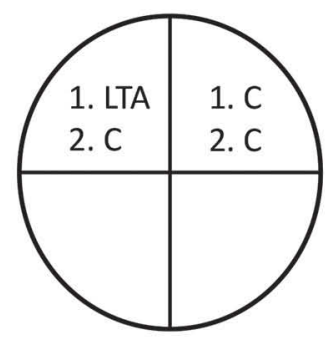

E.

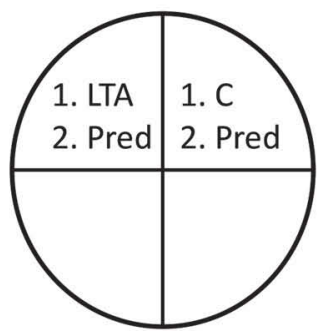

C.

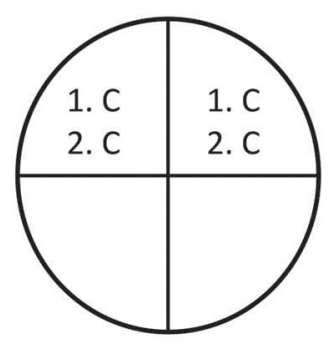

F.

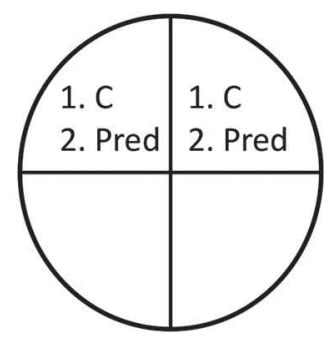

Figure 1. Experimental design: at $0 \mathrm{~h}$, cows received a co-injection in 2 treatment quarters denoted by 1 and 2 on the figure. Six treatment groups were used: LPS $(0.2 \mu \mathrm{g}$ of LPS; A), LTA (20 $\mu \mathrm{g}$ of LTA; B), control (C), LPS PRED (0.2 $\mu \mathrm{g}$ of LPS, $30 \mathrm{mg}$ of PRED; D), LTA PRED (20 $\mathrm{mg}$ of LTA, $30 \mathrm{mg}$ of PRED; E), and control PRED (10 mL of sterile saline, $30 \mathrm{mg}$ of PRED; F). LTA = lipoteichoic acid; C = saline control; $\mathrm{PRED}=$ prednisolone. Treatment quarters were randomly assigned for each cow to ensure no sampling bias. 
of the standards. Absorbance measurements were read on the Synergy Mx plate reader (BioTek Instruments). The standard curve was 400, 200, 100, 50, 25, 12.5, and $6.25 \mathrm{ng} / \mathrm{mL}$ and the limit of detection was $6.25 \mathrm{ng} /$ $\mathrm{mL}$. The inter- and intra-assay coefficients of variation were 4.95 and $7.23 \%$, respectively. All analyses were performed in duplicate.

$\boldsymbol{\alpha}-\boldsymbol{L} \boldsymbol{A}$. The concentration of $\alpha-\mathrm{LA}$ in plasma samples was analyzed by ELISA using a bovine-specific commercial kit (Bethyl Laboratories) according to the manufacturer's instructions. Plasma samples were diluted in wash buffer $(50 \mathrm{~m} M$ Tris, $0.14 \mathrm{M} \mathrm{NaCl}, 0.05 \%$ Tween 20 , adjusted to $\mathrm{pH} 8.0$ ) to ensure the samples were in range of the standards. Absorbance measurements were read on the Synergy Mx plate reader (BioTek Instruments). The standard curve was 50, 25, 12.5, 6.25, 3.12, 1.56 , and $0.78 \mathrm{ng} / \mathrm{mL}$ and the limit of detection was $0.78 \mathrm{ng} / \mathrm{mL}$. The inter- and intra-assay coefficients of variation were 4.17 and $9.94 \%$, respectively. All analyses were performed in duplicate.

\section{Statistical Analysis}

All results are presented as means \pm SEM. Statistical analysis of SCC (at a logarithmic scale, $\log _{10}$ ), $\operatorname{IgG}, \mathrm{SA}$, $\mathrm{LDH}, \alpha-\mathrm{LA}$, and rectal temperature was performed using ANOVA from the mixed procedure of SAS (version 9.4; SAS Institute Inc., Cary, NC) with Tukey-Kramer adjustment. The model included time, treatment, and the interaction between both (time $\times$ treatment) as fixed effects and cow as the repeated subject. The values for the 2 control quarters in control cow and control cow PRED groups were averaged for comparison to the other groups in the trial. Control quarters from LPS and LTA challenged cows were all treated as the control quarters as there were no statistical differences. Values were considered significant when $P<0.05$.

\section{RESULTS}

\section{Bacteriology}

All cows were free of mastitis-causing pathogens in all quarters.

\section{Rectal Temperature}

Rectal temperature was not different between groups and did not change during the experiment (data not shown).

\section{Control Quarters and Animals}

We found no statistical differences in SCC, and LDH, $\mathrm{IgG}$, or SA concentrations between control quarters, control cows, control PRED quarters, and control PRED cows (Figures 2C, 3C, 4C, 5C). Therefore, LPS and LTA quarters were only statistically compared with the control quarter, not the control cow. The LPS PRED and LTA PRED quarters were only compared with the control PRED quarters.

\section{SCC}

Compared with control quarters, SCC was higher from $3 \mathrm{~h}$ after challenge in LPS quarters and from 3.75 $\mathrm{h}$ after challenge in LTA quarters until the end of the experiment. There were no statistical differences between LPS and LTA challenged quarters throughout the experiment. In LPS PRED quarters, SCC was higher than in control PRED quarters from $5 \mathrm{~h}$ after challenge until the end of the experiment, but we observed no significant differences between the LTA PRED and control PRED quarters. No differences were noted between LPS and LPS PRED quarters (Figure 2A), although SCC was higher in the LTA quarters than in the LTA PRED quarters at 4.5 and $5 \mathrm{~h}$ after challenge and then from $6.5 \mathrm{~h}$ until the end of the experiment (Figure 2B). The SCC was higher in LPS PRED quarters than LTA PRED quarters at $5 \mathrm{~h}$ after challenge and then from 6 $h$ until the end of the experiment.

A significant elevation of SCC compared with time 0 was detectable in the LPS quarters at $2 \mathrm{~h}$ after challenge and then from $2.5 \mathrm{~h}$ until the end of the experiment, and in the LTA quarters from $3 \mathrm{~h}$ after challenge until the end of the experiment. In the LPS PRED quarters an elevation of SCC was detectable from 3.5 $\mathrm{h}$ after challenge until the end of the experiment. We found no significant increase compared with time 0 in the LTA PRED quarters, control quarters, control PRED quarters, control cows, or control PRED cows throughout the experiment.

\section{$L D H$}

Lactate dehydrogenase activity in milk was higher in the LPS quarters than the control quarters from 3.25 $\mathrm{h}$ until the end of the experiment and was higher than in LTA quarters from $6.5 \mathrm{~h}$ until the end of the experiment. The LPS quarters showed higher LDH activity in milk than the LPS PRED quarters at 7 and $7.5 \mathrm{~h}$ after challenge (Figure 3A). The LPS PRED quarters had higher LDH than the control PRED quarters only at $6 \mathrm{~h}$ after challenge. There were no differences between LTA and control quarters, LTA and LTA PRED quarters (Figure 3B), and LPS PRED and LTA PRED quarters.

Lactate dehydrogenase was significantly elevated from time 0 in the LPS quarters from $5 \mathrm{~h}$ until the end 
WALL ET AL.
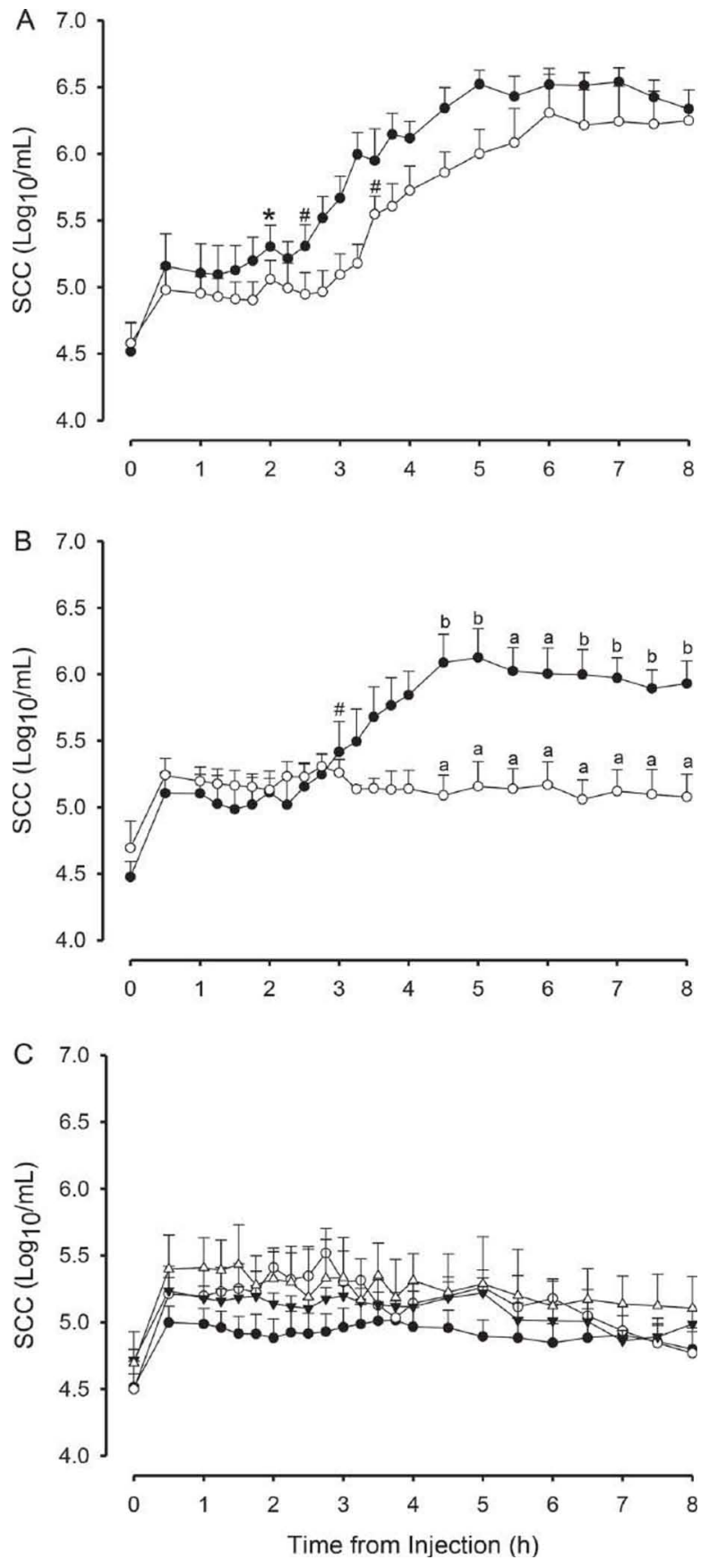

Figure 2. Somatic cell count (presented in log scale) in LPS (0.2 $\mu \mathrm{g}$ of LPS) and LPS PRED [0.2 $\mu \mathrm{g}$ of LPS, $30 \mathrm{mg}$ of prednisolone (PRED)] quarters (A), lipoteichoic acid (LTA; $20 \mu \mathrm{g}$ of LTA) and LTA PRED (20 $\mu \mathrm{g}$ of LTA, $30 \mathrm{mg}$ of PRED) quarters (B), and all controls (C; $10 \mathrm{~mL}$ of saline with or without $30 \mathrm{mg}$ of PRED). Data are presented as means \pm SEM. For (A), $\bullet=$ mean SCC in LPS quarters, $\mathrm{O}=$ mean SCC in LPS PRED quarters; (B) $\bullet=$ mean SCC in LTA quarters, $\mathrm{O}=$ mean SCC in LTA PRED quarters; $(\mathrm{C}) \bullet=$ mean SCC in control quarters, $\mathrm{O}=$ mean $\mathrm{SCC}$ in control cows, $\boldsymbol{\nabla}=$ mean SCC in control PRED quarters, $\boldsymbol{\Delta}=$ mean SCC in control PRED cows. Within a time point, differing letters (a,b) indicate significance between groups $(P<0.05)$; an asterisk $\left.{ }^{*}\right)$ indicates significant elevation compared with time point $0(P<0.05)$; a pound sign $(\#)$ indicates time point of significant elevation (compared with time point 0 ) until the end of the experiment $(P<0.05)$.
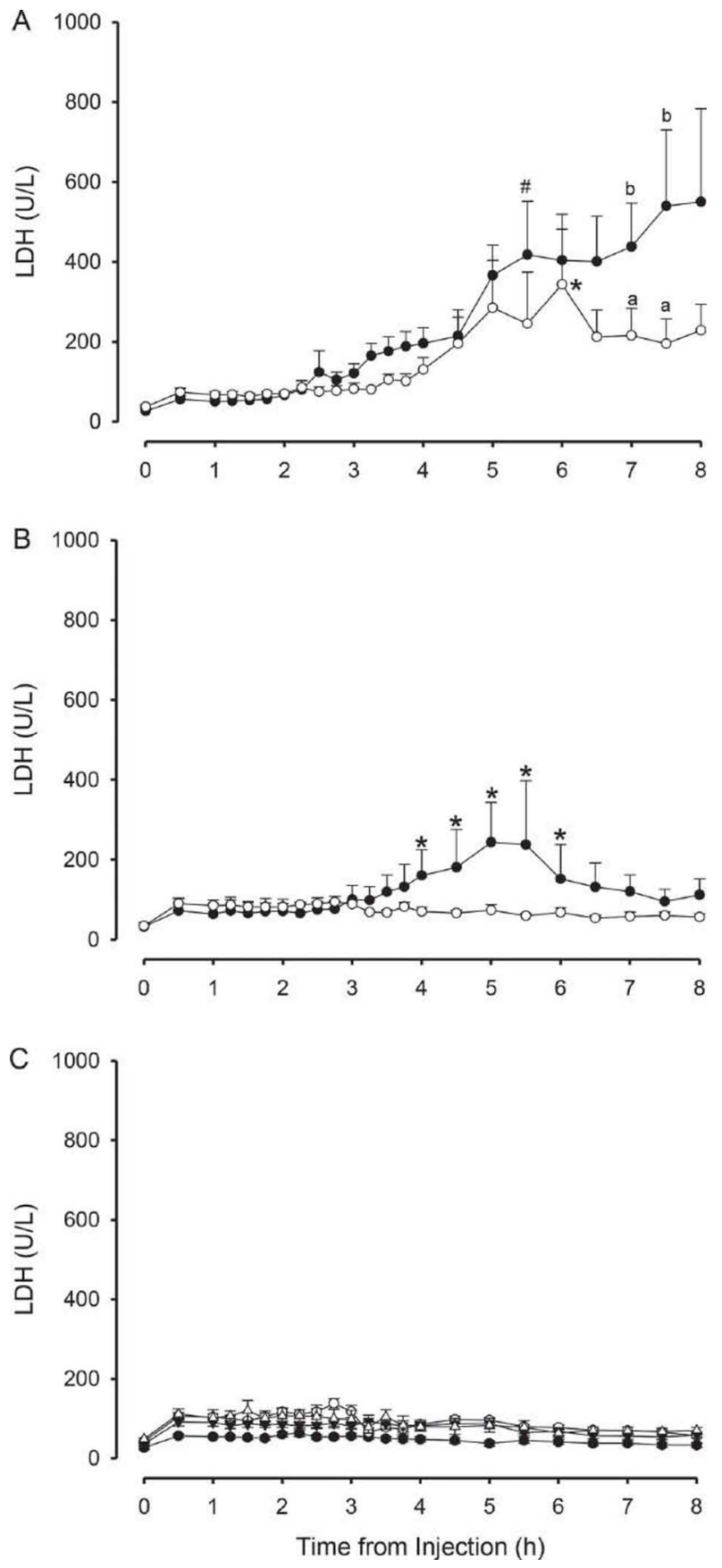

Figure 3. Lactate dehydrogenase (LDH) activity in milk of LPS $(0.2 \mu \mathrm{g}$ of LPS $)$ and LPS PRED [0.2 $\mu \mathrm{g}$ of LPS, $30 \mathrm{mg}$ of prednisolone (PRED)] quarters (A), lipoteichoic acid (LTA; $20 \mu \mathrm{g}$ of LTA) and LTA PRED (20 $\mu \mathrm{g}$ of LTA, $30 \mathrm{mg}$ of PRED) quarters (B), and of all controls (C; $10 \mathrm{~mL}$ of saline with or without $30 \mathrm{mg}$ of PRED). Data are presented as means \pm SEM. For $(\mathrm{A}), \bullet=$ mean LDH in LPS quarters, $\mathrm{O}=$ mean LDH in LPS PRED quarters; (B), $\bullet=$ mean LDH in LTA quarters, $\bigcirc=$ mean LDH in LTA PRED quarters; $(\mathrm{C}), \bullet=$ mean LDH in control quarters, $\mathrm{O}=$ mean LDH in control cows, $\boldsymbol{\nabla}=$ mean LDH in control PRED quarters, $\boldsymbol{\Delta}=$ mean LDH in control PRED cows. Within a time point, differing letters $(\mathrm{a}, \mathrm{b})$ indicate significance $(P<$ $0.05)$ between groups; an asterisk $(*)$ indicates significant elevation compared with time point $0(P<0.05)$; a pound sign $(\#)$ indicates time point of significant elevation until the end of the experiment $(P$ $<0.05)$. 

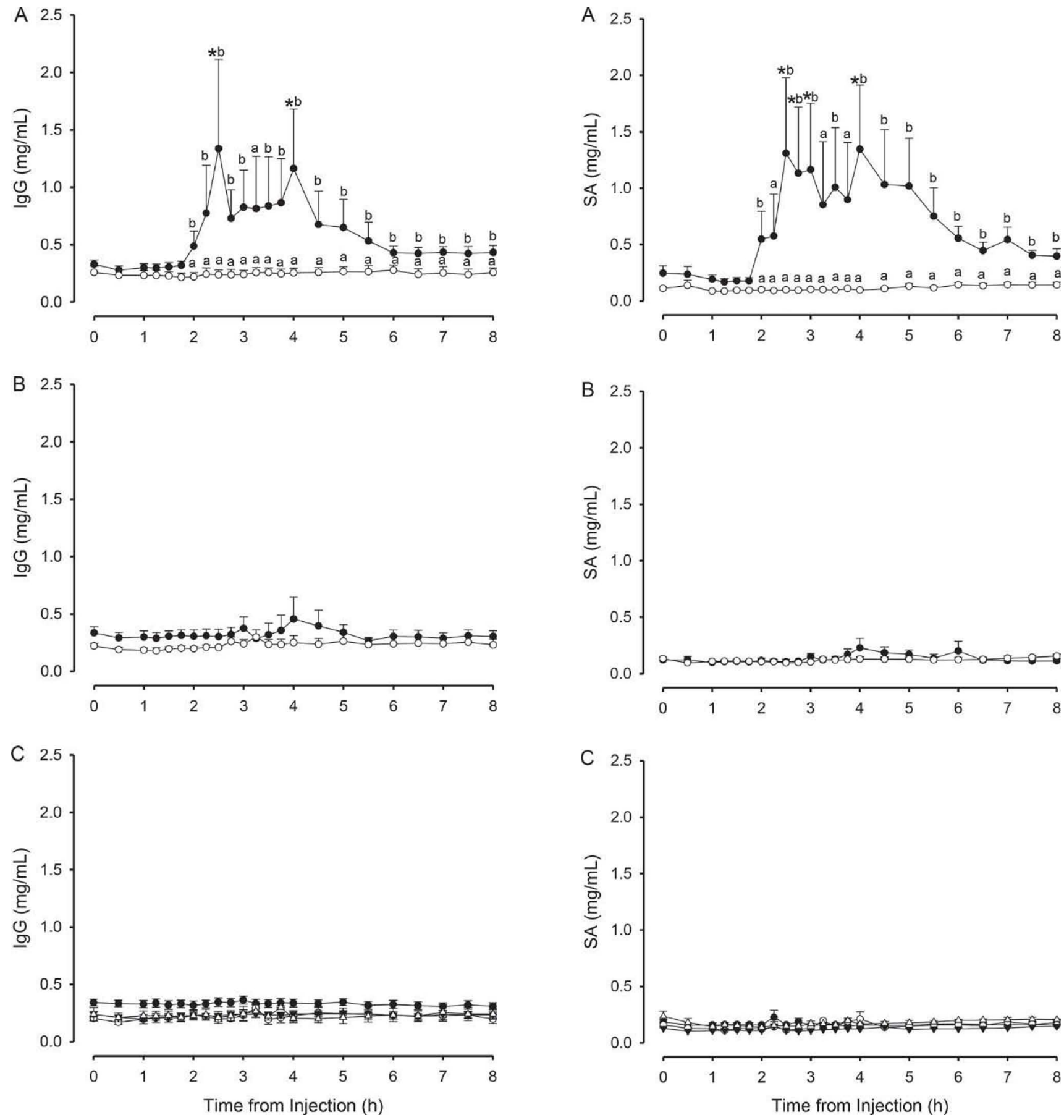

Figure 4. Immunoglobulin $\mathrm{G}$ concentrations in LPS $(0.2 \mu \mathrm{g}$ of LPS) and LPS PRED [0.2 $\mu \mathrm{g}$ of LPS, $30 \mathrm{mg}$ of prednisolone (PRED)] quarters (A), lipoteichoic acid (LTA; $20 \mu \mathrm{g}$ of LTA) and LTA PRED (20 $\mu \mathrm{g}$ of LTA, $30 \mathrm{mg}$ of PRED) quarters (B), and of all controls (C; $10 \mathrm{~mL}$ of saline with or without $30 \mathrm{mg}$ of PRED). Data are presented as means \pm SEM. For $(A), \bullet=$ mean IgG in LPS quarters, $\bigcirc=$ mean IgG in LPS PRED quarters; (B), $\bullet=$ mean IgG in LTA quarters, $\bigcirc$ $=$ mean IgG in LTA PRED quarters; $(\mathrm{C}), \boldsymbol{\bullet}=$ mean IgG in control quarters, $\bigcirc=$ mean IgG in control cows, $\boldsymbol{\nabla}=$ mean IgG in control PRED quarters, $\boldsymbol{\Lambda}=$ mean IgG in control PRED cows. Within a time point, differing letters $(\mathrm{a}, \mathrm{b})$ indicate significance between groups $(P$ $<0.05)$; an asterisk $(*)$ indicates significant elevation compared with time point $0(P<0.05)$.

Figure 5. Serum albumin (SA) concentrations in milk of LPS $(0.2$ $\mu \mathrm{g}$ of LPS) and LPS PRED [0.2 $\mu \mathrm{g}$ of LPS, $30 \mathrm{mg}$ of prednisolone (PRED)] quarters (A), lipoteichoic acid (LTA; $20 \mu \mathrm{g}$ of LTA) and LTA PRED (20 $\mu \mathrm{g}$ of LTA, $30 \mathrm{mg}$ of PRED) quarters (B), and of all controls (C; $10 \mathrm{~mL}$ of saline with or without $30 \mathrm{mg}$ of PRED). Data are presented as means \pm SEM. For (A), $\bullet=$ mean SA in LPS quarters, $0=$ mean SA in LPS PRED quarters; (B), $\bullet=$ mean SA in LTA quarters, $O=$ mean SA in LTA PRED quarters; $(\mathrm{C}), \bullet=$ mean SA in control quarters, $\bigcirc=$ mean SA in control cows, $\boldsymbol{\nabla}=$ mean SA in control PRED quarters, $\boldsymbol{\Delta}=$ mean SA in control PRED cows. Within a time point, differing letters $(a, b)$ indicate significance between groups $(P<0.05)$; an asterisk $(*)$ indicates significant elevation compared with time point $0(P<0.05)$. 


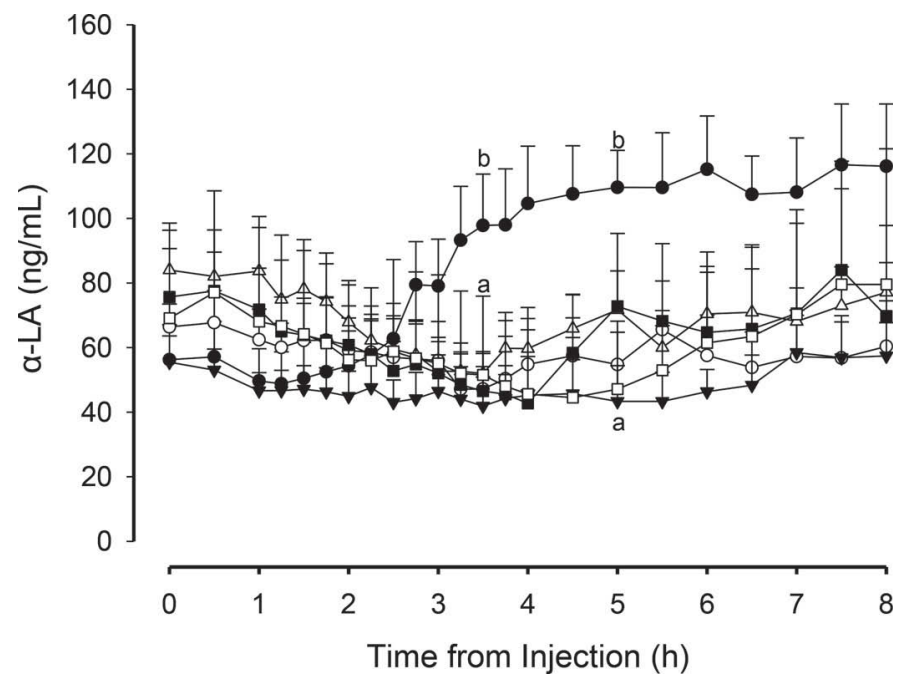

Figure 6. $\alpha$-Lactalbumin concentration in plasma in all groups. Data are presented as means \pm SEM; $\bullet=$ mean $\alpha$-LA in LPS $(0.2$ $\mu \mathrm{g}$ of LPS) cows, $\bigcirc=$ mean $\alpha$-LA in lipoteichoic acid (LTA; $20 \mu \mathrm{g}$ of LTA) cows, $\boldsymbol{\nabla}=$ mean $\alpha$-LA in control (10 mL of saline) cows, $\boldsymbol{\Lambda}$ $=$ mean $\alpha$-LA in LPS PRED $[0.2 \mu \mathrm{g}$ of LPS, $30 \mathrm{mg}$ of prednisolone (PRED)] cows, = mean $\alpha$-LA in LTA PRED (20 $\mu \mathrm{g}$ of LTA, $30 \mathrm{mg}$ of PRED) cows, $\square=$ mean $\alpha$-LA in control PRED (10 mL of sterile saline, $30 \mathrm{mg}$ of PRED) cows. Within a time point, differing letters $(\mathrm{a}, \mathrm{b})$ indicate significance between groups $(P<0.05)$.

of the experiment, only at $6 \mathrm{~h}$ for LPS PRED quarters, and from $4 \mathrm{~h}$ to $6 \mathrm{~h}$ in the LTA group. We observed no elevation from time 0 for the LTA PRED, control quarters, control PRED quarters, control cows, and control PRED cows.

\section{IgG}

Immunoglobulin G concentration was higher in LPS quarters compared with control quarters from $2 \mathrm{~h}$ after challenge until the end of the experiment with the exception of $3.25,6,6.5$, and 7.5 h. In LPS quarters, IgG concentrations were higher than in LPS PRED quarters (Figure 4A) from $2 \mathrm{~h}$ after challenge until the end of the experiment, with the exception of $3.25 \mathrm{~h}$. The LPS quarters were also higher in $\operatorname{IgG}$ concentrations than the LTA quarters at $2.5,2.75,3,3.5,3.75,4,5,5.5$, and $7 \mathrm{~h}$ after challenge. We observed no differences in IgG concentrations between LTA and control quarters, LPS PRED and control PRED quarters, LTA and LTA PRED quarters (Figure 4B), or LPS PRED and LTA PRED quarters.

Immunoglobulin $G$ was significantly elevated from time 0 in the LPS group at 2.5 and $4 \mathrm{~h}$ after challenge. No significant elevation was detected in LTA quarters, LPS PRED quarters, LTA PRED quarters, control quarters, control PRED quarters, control cows, and control PRED cows.

\section{$S A$}

Serum albumin concentrations were higher in milk of LPS quarters compared with control quarters from 2 $\mathrm{h}$ after challenge until the end of the experiment, with the exception of 2.25 and $3.25 \mathrm{~h}$, and higher compared with the LPS PRED quarters from $2 \mathrm{~h}$ until the end of the experiment, with the exception of 2.25, 3.25, and $3.75 \mathrm{~h}$ (Figure 5A). The LPS quarters also showed higher SA concentrations in milk than LTA quarters at $2,2.5$, and $3 \mathrm{~h}$ after challenge and then from $4 \mathrm{~h}$ until the end of the experiment. No differences were noted between LTA and control quarters, LPS PRED and control PRED quarters, LTA and LTA PRED quarters (Figure 5B), or LPS PRED and LTA PRED quarters.

Serum albumin was significantly elevated from time 0 only in milk of the LPS quarters from 2.5 to $3 \mathrm{~h}$ and at $4 \mathrm{~h}$. We found no significant elevation in milk of LTA quarters, LPS PRED quarters, LTA PRED quarters, control quarters, control PRED quarters, control cows, and of control PRED cows.

\section{$\alpha-L A$}

$\alpha$-Lactalbumin concentration in plasma of LPSchallenged cows was significantly higher than in plasma of LTA-challenged cows at $3.5 \mathrm{~h}$ and higher than in control cows at $5 \mathrm{~h}$ after challenge. There were no other significant differences in $\alpha$-LA plasma concentrations between groups or compared with time 0 (Figure 6).

\section{DISCUSSION}

In mastitis therapy, glucocorticoids are frequently used in addition to antibiotic treatment to reduce inflammation and, in Europe, intramammary antibiotic formulations containing PRED are available. It is known that PRED can alter the blood-milk barrier by inducing the rearrangement of tight junctions (Stelwagen et al., 1998). In addition, PRED can bind to the glucocorticoid receptor on immune cells, therefore blocking the production of proinflammatory cytokines (Rhen and Cidlowski, 2005) and affecting the migration of immune cells (Schwiebert et al., 1996). Due to these facts, it is important to understand the effect of this glucocorticoid on the migration of immune cells and the transfer of various blood proteins in both clinical and subclinical mastitis cases. Clinical mastitis (e.g., through infection with the gram-negative pathogen $E$. coli) is associated with a greater transfer of blood proteins into milk and a greater stimulation of the immune system as compared with subclinical mastitis, which is often caused by the gram-positive pathogen $S$. aureus (Bannerman et al., 2004; Wellnitz and Bruckmaier, 2011). 
In previous studies using the bacterial cell wall components LPS and LTA to induce mastitis, our group has shown a differential blood to milk transfer of proteins such as immunoglobulins (Wellnitz et al., 2013). Dosages of LPS and LTA were chosen to standardize the immune response based on a similar SCC increase, which allows for the quantitative comparison of additional factors (Wellnitz and Bruckmaier, 2011). This similar SCC increase was also achieved in the present study. Relatively low doses of LPS and LTA were chosen to induce a moderate response and thus to allow an optimal investigation of differences in blood-milk barrier permeability. This low dose of endotoxins likely explains why we found no differences in rectal temperature between groups. Intramammary administration of LPS in higher doses usually induces fever and a systemic response in cows (Zarrin et al., 2014).

To determine the blood-milk barrier permeability during a mammary infection and the effect of PRED on the permeability of this barrier, the paracellular transfer of several blood proteins can be measured (Nguyen and Neville, 1998). Serum albumin is a blood protein which is found in higher concentrations in milk if the permeability of the blood-milk barrier is increased (Stelwagen et al., 1994; Wall et al., 2015). In the present study, quarters challenged with LPS had an increased SA concentration, but PRED reduced this increase to control quarter level. This shows that PRED reduces the increase of blood-milk barrier permeability by LPS. Some evidence exists that SA can be directly synthesized by cells in mammary tissue (Phillippy and McCarthy, 1979) and that LPS can accelerate this synthesis (Shamay et al., 2005). However, this likely had minimal effect on its suitability as an indicator of blood-milk barrier permeability in the current study, as the direct effect of PRED on the blood-milk barrier could reduce SA concentrations to nontreated quarter levels. Lactate dehydrogenase, a ubiquitous enzyme in the cow that is present in all cells and drives the interconversion of lactate and pyruvate, is mainly transferred from blood to milk when there is increased permeability of the bloodmilk barrier (Symons and Wright, 1974; Lehmann et al., 2013), although a small fraction of LDH in milk can be caused by the additional release of LDH by damaged cells in the mammary gland (Bogin et al., 1977). Upon examination, PRED had an effect on the transfer of this protein in both LPS- and LTA-challenged quarters. The concentration of LDH was elevated from 4 to $6 \mathrm{~h}$ after LTA challenge; however, this increase was diminished in the LTA PRED quarters. In quarters challenged with LPS, PRED reduced LDH to control quarter levels. The reduction of both SA and LDH in milk was in agreement with Wellnitz et al. (2014), who also observed a decrease in SA and $\mathrm{LDH}$ concentra- tion in quarters administered LPS and PRED and thus an increase in barrier integrity by PRED during LPS mastitis.

Another blood component that is transferred from blood to milk is IgG. Immunoglobulin G is likely to contribute to the immune defense during mastitis, which is confirmed by the positive effects of vaccination against mastitis pathogens. Higher amounts of $\mathrm{IgG}$ are transferred into the mammary secretion if the permeability of the blood-milk barrier is increased. In the present study, IgG was highly elevated in LPS quarters and the addition of PRED reduced this increase to control quarter levels. These results clearly show that PRED effects on the blood-milk barrier can reduce the IgG transfer from blood to milk. As IgG is the major opsonin for phagocytosis (Burton and Erskine, 2003), these PRED effects can have an influence on the cure of mastitis if antibodies against the inducing pathogen are available in the blood (i.e., after vaccination). Interestingly, this effect of IgG reduction in milk by PRED treatment obviously plays a more important role in LPS-induced mastitis compared with LTA-induced mastitis.

Prednisolone does not only affect the blood-milk barrier, it also binds to the glucocorticoid receptor on immune cells and can block the production of proinflammatory cytokines (Rhen and Cidlowski, 2005). This effect of PRED can directly influence the migration of immune cells into the milk (Schwiebert et al., 1996) and, in addition, Ziege et al. (2000) showed that PRED administration could limit the migration of PMNL in vitro. In the present study, PRED had no effect on SCC increase in LPS-challenged quarters. This confirms the results from Wellnitz et al. (2014), who showed no influence of intramammary PRED on quarters challenged with LPS. It is clear that the influence on chemotaxis and the closure of the blood-milk barrier during LPS mastitis is not strong enough to reduce the SCC. However, although PRED did not have an effect on the total number of migrating cells in LPS challenged quarters, the migration was slower (e.g., the SCC of LPS quarters was already increased at $2 \mathrm{~h}$ and the SCC of LPS and PRED quarters was not increased until $3.5 \mathrm{~h}$ after challenge). In contrast to the LPS-challenged quarters, intramammary PRED had a strong influence on cell migration in the LTA-challenged quarters, decreasing the SCC to control quarter levels. This indicates a stronger effect of PRED on cell migration in LTA-induced mastitis compared with LPS-induced mastitis. GriesbeckZilch et al. (2008) showed that mammary epithelial cells stimulated with either $E$. coli or $S$. aureus had differing expression profiles of proinflammatory cytokines and chemokines, which could explain differences in cell migration. It seems that compared with LTA, LPS is 
such a strong stimulus that the addition of PRED does not completely stop the production of proinflammatory cytokines and chemokines that promote the migration of immune cells.

Changes in the blood-milk barrier can also affect cell migration. It is likely that in LPS-challenged quarters, cells are also entering the milk due to cell degradation of mammary epithelial cells which occurs in LPS but not in LTA treatment (Wellnitz et al., 2016). This could be a mechanism on which PRED may have no effect on the integrity of the blood-milk barrier. It is also possible that the blood-milk barrier can exhibit selectivity, as a decrease occurs in the transfer of blood proteins but not migrating cells.

In all animals $\alpha$-LA (a strict milk protein) was measured in blood. This protein is known to increase in blood when the blood-milk barrier is permeable (McFadden et al., 1987). At only some time points were significant differences noted in $\alpha$-LA concentrations between groups (e.g., $\alpha$-LA concentration was higher in blood from LPS- than from LTA-challenged cows at $3.5 \mathrm{~h}$ and higher than the control cows at $5 \mathrm{~h}$ after challenge); however, no significant increase was noted compared with time 0 in any group. Although these results show a different impairment of the blood-milk barrier by LPS and LTA treatment, a more pronounced transfer of $\alpha$-LA from milk to blood was expected. Blood components in milk clearly show an impairment of the blood-milk barrier and $\alpha$-LA should cross through the same paracellular space as blood proteins that are transferred to milk. Furthermore, we found no differences in $\alpha$-LA between cows treated with LPS or LPS and PRED. In a similar study performed in our laboratory (Wellnitz et al., 2015), $\alpha$-LA concentration was also not increased from time 0 in LPS-challenged animals. In Wellnitz et al. (2015), it was argued that $\alpha$-LA concentration in blood was already increased after milking due to mammary engorgement between afternoon and morning milking, and this protein needs $8 \mathrm{~h}$ to return to baseline values in the blood (Stelwagen et al., 1997). This is different compared with blood proteins, such as SA, entering the milk due to mammary engorgement, as it would have been milked out before the experiment. This reasoning could explain why we found no differences between groups in the current study.

Importantly, concentrations of both SA and IgG were highly variable in LPS-challenged quarters between sampling time points in the current study, as seen by the increases and decreases in concentration between 2 and $4 \mathrm{~h}$. These results could be due to the low dosage of LPS and individual variation between cows. It is possible that low doses could reveal susceptibility to LPS in individual animals, and this individual susceptibility has been reported in bovine dermal fibroblasts under experimentally induced $E$. coli mastitis conditions (Kandasamy et al., 2011). Furthermore, earlier records for previous diseases or vaccination against mastitiscausing pathogens of the cows were not available. This could have also influenced the immune competency of the cows' mammary glands, as cows can have an increased immune response to antigens after first contact (Rainard and Paape, 1997).

In our study, control animals (cows that received only saline or cows that received saline and PRED) were used to determine if any differences existed between quarters in animals that received LPS or LTA compared with cows that received only the control treatment or only PRED. The results showed no differences in control quarters from cows that received LPS, LTA, only PRED, or only saline; therefore, just the control quarters from LPS- or LTA-challenged animals were used for statistical comparisons. Control quarters within an animal have long been used for challenge experiments (Bannerman et al., 2004; Schmitz et al., 2004), and the current results show that this method is appropriate. Some evidence exists of cross-talk between quarters at a transcriptional level in E. coli- and $S$. aureus-challenged cows (Jensen et al., 2013); however, strictly looking at proteins as indicators of blood-milk barrier permeability, no differences could be detected. This also confirms no effect of intramammary PRED alone on the blood-milk barrier in healthy udders, as we found no differences compared with control animals without PRED.

\section{CONCLUSIONS}

The results of the present study confirm our hypothesis that intramammary administration of the glucocorticoid PRED can manipulate the differential impairment of the blood-milk barrier induced by LPS or LTA challenge. This is shown by a decrease in the transfer of blood proteins such as LDH, SA, and IgG into milk in LPS-challenged quarters. In addition, intramammary PRED decreases the migration of PMNL in LTA-challenged quarters. Glucocorticoids, mainly PRED, are sometimes used in the dairy industry to reduce inflammation associated with mastitis and to also quickly restore milk quality. However, it appears that PRED also has implications in impairing the immune system of the mammary gland by reducing the concentration of IgG in milk and the migration of immune cells. This could have a negative effect on the cure of mastitis if antibodies against the pathogen are available (e.g., after vaccination against mastitis), and due to the 
fact that immune cells are the effectors for eliminating pathogens. Therefore, PRED could have both helpful and harmful attributes in mastitis treatment.

\section{ACKNOWLEDGMENTS}

This study was supported by the Swiss National Science Foundation (Bern, Switzerland; grant no. 149460). The authors also thank Claudine Morel, Yolande Zbinden, and Jennifer Fleury (Veterinary Physiology, Vetsuisse Faculty University of Bern, Switzerland) for their technical assistance.

\section{REFERENCES}

Bannerman, D. D., M. J. Paape, J. W. Lee, X. Zhao, J. C. Hope, and P. Rainard. 2004. Escherichia coli and Staphylococcus aureus elicit differential innate immune responses following intramammary infection. Clin. Diagn. Lab. Immunol. 11:463-472.

Bogin, E., G. Ziv, J. Avidar, B. Rivetz, S. Gordin, and A. Saran. 1977. Distribution of lactate dehydrogenase isoenzymes in normal and inflamed bovine udders and milk. Res. Vet. Sci. 22:198-200.

Burton, J. L., and R. J. Erskine. 2003. Immunity and mastitis. Some new ideas for an old disease. Vet. Clin. North Am. Food Anim. Pract. 19:1-45.

Griesbeck-Zilch, B., H. H. D. Meyer, Ch. Kühn, M. Schwerin, and O. Wellnitz. 2008. Staphylococcus aureus and Escherichia coli cause deviating expression profiles of cytokines and lactoferrin messenger ribonucleic acid in mammary epithelial cells. J. Dairy Sci. 91:2215-2224.

Hogan, J. S., R. N. Gonzales, R. J. Harmon, S. C. Nickerson, S. P. Oliver, J. W. Pankey, and K. L. Smith. 1999. Laboratory Handbook on Bovine Mastitis. Revised Ed. National Mastitis Council, Madison, WI.

Jensen, K., J. Günther, R. Talbot, W. Petzl, H. Zerbe, H.-J. Schuberth, H.-M. Seyfert, and E. J. Glass. 2013. Escherichia coli and Staphylococcus aureus induced mastitis differentially modulate transcriptional responses in neighbouring uninfected bovine mammary gland quarters. BMC Genomics 14:36.

Kandasamy, S., B. B. Green, A. L. Benjamin, and D. E. Kerr. 2011. Between-cow variation in dermal fibroblast response to lipopolysaccharide reflected in resolution of inflammation during Escherichia coli mastitis. J. Dairy Sci. 94:5963-5975.

Lehmann, M., O. Wellnitz, and R. M. Bruckmaier. 2013. Concomitant lipopolysaccharide-induced transfer of blood-derived components including immunoglobulins into milk. J. Dairy Sci. 96:889-896.

McFadden, T. B., R. M. Akers, and G. W. Kazmer. 1987. Alpha-lactalbumin in bovine serum: relationships with udder development and function. J. Dairy Sci. 70:259-264.

Nguyen, D. A., and M. C. Neville. 1998. Tight junction regulation in the mammary gland. J. Mammary Gland Biol. Neoplasia 3:233246

Phillippy, B. O., and R. D. McCarthy. 1979. Multi-origins of milk serum albumin in the lactating goat. Biochim. Biophys. Acta 584:298-303.

Rainard, P., and M. J. Paape. 1997. Sensitization of the bovine mammary gland to Escherichia coli endotoxin. Vet. Res. 28:231-238.

Rhen, T., and J. A. Cidlowski. 2005. Anti-inflammatory action of glucocorticoids-new mechanisms for old drugs. N. Engl. J. Med. 353:1711-1723.

Sandholm, M. 1976. Coagulation of serum by glutaraldehyde. Clin. Biochem. 9:39-41.

Schmitz, S., M. W. Pfaffl, H. H. D. Meyer, and R. M. Bruckmaier. 2004. Short term changes of mRNA expression of various inflam- matory factors and milk proteins in mammary tissue during LPSinduced mastitis. Domest. Anim. Endocrinol. 26:111-126.

Schwiebert, L. M., L. A. Beck, and C. Stellato. 1996. Glucocorticosteroid inhibition of cytokine production and relevance to antiallergic actions. J. Allergy Clin. Immunol. 97:143-152.

Shamay, A., R. Homans, Y. Fuerman, I. Levin, H. Barash, N. Silanikove, and S. J. Mabjeesh. 2005. Expression of albumin in nonhepatic tissues and its synthesis by the bovine mammary gland. J. Dairy Sci. 88:569-576.

Sipka, A., A. Gurjar, S. Klaessig, G. E. Duhamel, A. Skidmore, J. Swinkels, P. Cox, and Y. Schukken. 2013. Prednisolone and cefapirin act synergistically in resolving experimental Escherichia coli mastitis. J. Dairy Sci. 96:4406-4418.

Stahn, C., M. Löwenburg, D. W. Hommes, and F. Buttgereit. 2007. Molecular mechanisms of glucocorticoid action and selective glucocorticoid receptor agonists. Mol. Cell. Endocrinol. 275:71-78.

Stelwagen, K., V. C. Farr, H. A. McFadden, C. G. Prosser, and S. R. Davis. 1997. Time course of milk accumulation-induced opening of mammary tight junctions, and blood clearance of milk components. Am. J. Physiol. 273:R379-386.

Stelwagen, K., I. Politis, J. H. White, B. Zavizion, C. G. Prosser, S. R. Davis, and V. C. Farr. 1994. Effect of milking frequency and somatotropin on the activity of plasminogen activator, plasminogen, and plasmin in bovine milk. J. Dairy Sci. 77:3577-3583.

Stelwagen, K., D. C. van Espen, G. A. Verkerk, H. A. McFadden, and V. C. Farr. 1998. Elevated plasma cortisol reduces permeability of mammary tight junctions in the lactating bovine mammary gland. J. Endocrinol. 159:173-178.

Symons, D. B. A., and L. J. Wright. 1974. Changes in bovine mammary gland permeability after intramammary exotoxin infusion. J. Comp. Pathol. 84:9-17.

Wall, S. K., J. J. Gross, E. C. Kessler, K. Villez, and R. M. Bruckmaier. 2015. Blood-derived proteins in milk: Indicators of active or passive transfer. J. Dairy Sci. 98:7748-7756.

Wellnitz, O., E. T. Arnold, M. Lehmann, and R. M. Bruckmaier. 2013. Short communication: Differential immunoglobulin transfer during mastitis challenge by pathogen-specific components. J. Dairy Sci. 96:1681-1684

Wellnitz, O., and R. M. Bruckmaier. 2011. Lipopolysaccharide and lipoteichoic acid induce different immune responses in the bovine mammary gland. J. Dairy Sci. 94:5405-5412.

Wellnitz, O., S. K. Wall, M. Saudenova, and R. M. Bruckmaier. 2014. Effect of intramammary administration of prednisolone on the blood-milk barrier during the immune response of the mammary gland to lipopolysaccharide. Am. J. Vet. Res. 75:595-601.

Wellnitz, O., C. Zbinden, X. Huang, and R. M. Bruckmaier. 2016. Short communication: Differential loss of bovine mammary epithelial barrier integrity in response to lipopolysaccharide and lipoteichoic acid. J. Dairy Sci. 99:4851-4856. http://dx.doi.org/10.3168/ jds.2016-10927.

Wellnitz, O., C. Zbinden, J. Lüttgenau, H. Bollwein, and R. M. Bruckmaier. 2015. Different chronological patterns of appearance of blood derived milk components during mastitis indicate different mechanisms of transfer from blood into milk. J. Dairy Res. $82: 322-327$.

Zarrin, M., O. Wellnitz, H. A. van Dorland, and R. M. Bruckmaier. 2014. Induced hyperketonemia affects the mammary immune response during lipopolysaccharide challenge in dairy cows. J. Dairy Sci. 97:330-339.

Zettl, K. S., M. D. Sjaastad, P. M. Riskin, G. Parry, T. E. Machen, and G. L. Firestone. 1992. Glucocorticoid-induced formation of tight junctions in mouse mammary epithelial cells in vitro. Proc. Natl. Acad. Sci. USA 89:9069-9073.

Ziege, S. U., H. F. Geerdes-Finge, M. Rau, U. Buchwald, and H. Lode. 2000. In vitro effects of interleukin-10, prednisolone, and GM-CSF on the non-specific immune function of human polymorphonuclear leukocytes and monocytes. Eur. J. Med. Res. 5:369-374. 